\title{
MEASUREMENT OF DIELECTRIC LOSS AT MILLIMETER RANGE IN THE LOW LOSS MATERIALS WITH ARBITRARY RATIO OF WAVELENGTH AND SAMPLE THICKNESS
}

\author{
E. E. Chigryai, B. M. Garin, R. N. Denisyuk \\ Fryazino Branch of Kotelnikov Institute of Radioengineering and Electronics of Russian \\ Academy of Sciences, Vvedensky Sq.1, Fryazino Moscow region 141190, Russia
}

The paper was received on October 3, 2018

\begin{abstract}
For the first time the measurement technique is developed for dielectric loss in the low loss materials at the long-wave part of the millimeter range of electromagnetic waves on the basis of compact open semi-symmetric confocal resonator for the samples with arbitrary ratio of the sample thickness and wavelength in the dielectric material. The loss in the aluminum oxide ceramics $\left(\mathrm{Al}_{2} \mathrm{O}_{3}\right)$ of the brand VK-99 was measured at room temperature at the frequency $69.4 \mathrm{GHz}: \tan \delta=$ $3.1 \cdot 10^{-4}$. This value is close to the corresponding value in the aluminium oxide ceramics $\mathrm{Al}_{2} \mathrm{O}_{3}$ of the Russian production of the brand $\mathrm{VK} 100 \mathrm{M}$, and it is lower than in the corresponding ceramics of the Chinese production [5]. In addition, this value is close to the loss in the single crystal of $\mathrm{Al}_{2} \mathrm{O}_{3}$ (sapphire). This indicates a very high quality of the modern Russian ceramics of aluminum oxide.
\end{abstract}

Key words: open resonator, millimeter range of electromagnetic waves, dielectric loss, low loss materials.

\section{Introduction}

In the works $[1,2]$ the features of the measurement for dielectric loss in the films and a thin plane-parallel plates (whose thickness is less than half of wavelength in the dielectric material) were considered. These measurements were carried out by a compact open semi-symmetric confocal resonator in which a sample is placed on a flat mirror, or at some distance from the mirror to increase the activity of the interaction of the sample with the electric field of the electromagnetic wave. The length of the resonator may change, and the resonator is adjusted for resonance at the selected frequency. The operating range of the resonator is $50-80 \mathrm{GHz}$. 
In [2] the dielectric loss was measured by this setup and technique in thin sample (the thickness of which was less than a half of wavelength in the material) of the silicon carbide $\mathrm{SiC}$ of polytype $6 \mathrm{H}(6 \mathrm{H}-\mathrm{SiC})$ at the frequency of $69.4 \mathrm{GHz}$.

In many cases, the samples of low loss materials, particularly ceramics, have a thickness that is more than half of wavelength in the dielectric sample [3-5]. In this work the measurement technique is upgraded to measure the dielectric loss in the samples whose thickness is of the order or greater than a half of the wavelength in the material.

The dielectric loss was measured in the sample of aluminum oxide ceramic $\mathrm{Al}_{2} \mathrm{O}_{3}$ of the brand VK-99.

\section{A technique of measuring the dielectric loss}

The measurement technique for the dielectric loss tangent $\tan \delta$ includes the measurement of the $Q$-factors of empty resonator without of a dielectric plate $Q_{0}$ and of the resonator with included dielectric plate in it $Q_{1}$.

For the measurement the open semi-symmetrical confocal resonator was used, similar to that which was used in [2]. In the Figure 1 such a resonator with the sample of dielectric plate is shown in a longitudinal section. The plate is placed on the end face of the annular absorber and covered with a copper mirror.

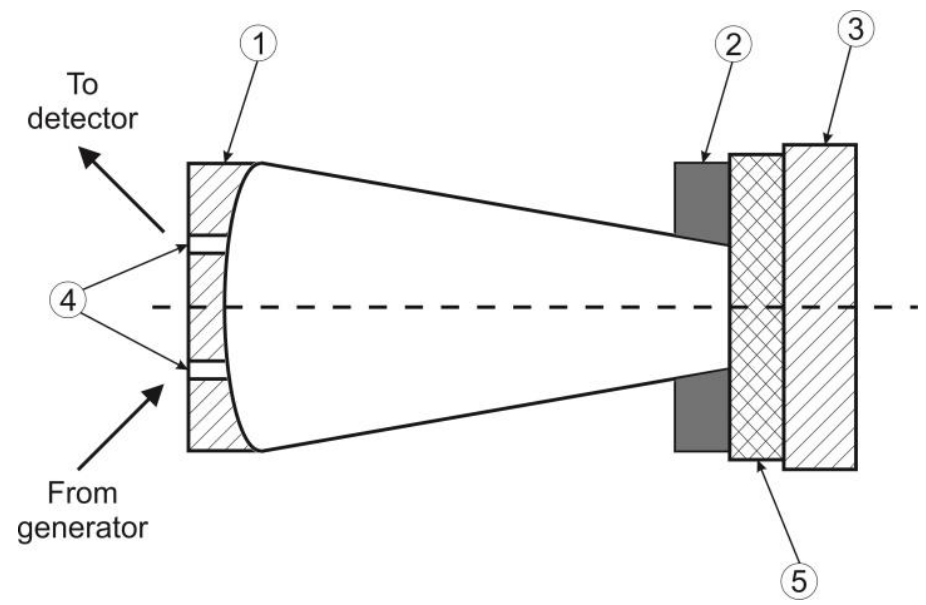

Figure 1 . The resonator with a sample: 1 - spherical metal mirror; 2 - flat ring absorber of the parasitic electromagnetic waves; 3 - flat metal mirror, 4 - connection holes; 5 - a sample of the dielectric plate.

The resonator consists of a spherical metal copper mirror with two coupling holes and a plane mirror. 
The ring absorber from the micarta provides a suppression of spurious microwaves in the resonator. The coupling of the source and detector with the resonator is performed by circular coupling holes with diameter of $1.25 \mathrm{~mm}$. The diameter of the spherical mirror is $40 \mathrm{~mm}$, the radius of curvature is $40 \mathrm{~mm}$, and the aperture diameter of the diaphragm with ring absorber is $25 \mathrm{~mm}$. The distance between the mirrors is varied by the differential screw mechanism from 17 to $25 \mathrm{~mm}$.

The samples are placed outside the diaphragm. The setup allows measurements of plane-parallel dielectric plates with arbitrary transverse shape and size allowing to cover fully the aperture of the diaphragm.

The complex reflection coefficient $r$ from the plate located on the copper mirror, is described by the expression [2]:

$$
r=\frac{\frac{1-n^{*}}{1+n^{*}}-r_{2} \cdot e^{2 i k h n^{*}}}{1-\left(\frac{1-n^{*}}{1+n^{*}}\right) \cdot r_{2} \cdot e^{2 i k h n^{*}}}
$$

Here $n^{*}=n \cdot[1+i \cdot(\tan \delta) / 2]$ is the complex refraction index in the dielectric plate, $k=$ $2 \pi f / c ; f$ is the frequency of electromagnetic field, $\mathrm{c}$ is the speed of light; $h$ is the plate thickness, $n$ is the real part of the refractive index, $\tan \delta=\varepsilon^{\prime \prime} / \varepsilon^{\prime}$ is the tangent of the dielectric, where $\varepsilon^{\prime}$ and $\varepsilon^{\prime \prime}$ are the real and imaginary parts of complex permittivity, $r_{2}$ is the coefficient of reflection from a flat metal copper mirror.

According to [6], $r_{2}$ is described by the expression:

$$
r_{2}=\sqrt{1-2\left(\frac{f}{\sigma}\right)^{1 / 2}},
$$

where $\sigma$ is the specific conductivity of the mirrors.

The quality factor of the empty resonator without dielectric plate is described by the expression:

$$
Q_{0}=\frac{k L}{\alpha_{0}}
$$


where $L$ is the length of the resonator; $\alpha_{0}$ is the loss of the electromagnetic wave in a single pass through the empty cavity.

When the thickness of the sample is about or more than the half the wavelength in the dielectric, there is a need to consider an additional increase in the electrical length of the resonator (taking into account the double passage of the wave through the dielectric plate) on the value of $\Delta=2 n \cdot h$, where $n$ is the refractive index, $h$ is the thickness of the sample. After placing the sample in the resonator, its quality factor $Q_{1}$ is described by expression (4):

$$
Q_{1}=\frac{k(L+\Delta)}{\alpha_{0}+\alpha_{1}}
$$

where $\alpha_{1}$ is the additional loss in the resonator, which is described by expression (5):

$$
\alpha_{1}=\left(\frac{Q_{0}}{Q_{1}} \cdot\left(\frac{L+\Delta}{h}\right)-1\right) \cdot \frac{k L}{Q_{0}}
$$

Dielectric losses $\tan \delta$ are calculated from the solution of the equation (6) [2]:

$$
\alpha(\tan \delta)-\alpha_{2}-\alpha_{1}=0
$$

Here the function $a(\tan \delta)$ is given by the expression: $\alpha(\tan \delta) \equiv 1-|r(\tan \delta)|^{2}$; $\alpha_{2}$ is the loss in the reflection from the copper mirror.

Note that in another technique, also based on open resonators [7-11], the measurement of dielectric loss is only possible when thickness of the sample equal to or a multiple of half the wavelength (i.e., only on the so-called "resonance" frequencies of the sample).

The method described in the present work, in contrast to the above, allows measuring the loss at an arbitrary ratio of wavelength and sample thickness.

\section{Dielectric loss in ceramics VK-99}

On the base of the technique developed in the present work, and by using the above-described resonator, the dielectric loss was measured in the sample of the 
ceramics of aluminum oxide $\mathrm{Al}_{2} \mathrm{O}_{3}$ of the brand VK-99, produced by the Open Public Company "Plant Magneton" (St. Petersburg). As a source of microwaves the Gunn's diode was used as monochromatic generator with the frequency of $69.4 \mathrm{GHz}$.

The ceramic sample had a thickness of $4 \mathrm{~mm}$, i.e. its thickness exceeded several times the half-wavelength in this material. It was located in front of the flat copper mirror and completely covered the entrance aperture of the resonator.

Earlier we measured the refractive index in this ceramics using the technique described in [2], based on the values of the "resonant" frequency of the sample: $n=$ 3.123. From the experimental data [12] the value of loss at reflection from the copper mirror $\alpha_{2}$ at the frequency of $69.4 \mathrm{GHz}$ is $7.8 \cdot 10^{-4}$. From the solution of equation (6) the obtained value of dielectric loss in this material at this frequency at room temperature: $\tan \delta=3 \cdot 1 \cdot 10^{-4}$. This value is close to the corresponding value in the aluminium oxide ceramics $\mathrm{Al}_{2} \mathrm{O}_{3}$ of the brand $\mathrm{VK} 100 \mathrm{M}$ produced by the Company "Plant Magneton" [5]. In addition, these values are close to the losses in the single crystal of $\mathrm{Al}_{2} \mathrm{O}_{3}$ (sapphire). It should also be noted that the relevant Chinese ceramics production losses are higher [5]. This indicates a very high quality of the modern Russian ceramics of aluminum oxide.

\section{Conclusion}

The technique is developed of the measurement of dielectric loss in the low loss materials in the millimeter range on the basis of compact open semi-symmetric confocal resonator with arbitrary ratio of the sample thickness and wavelength, including the cases when the sample thickness is of the order or more than the halfwavelength in the material.

The loss is measured in ceramics $\mathrm{Al}_{2} \mathrm{O}_{3}$ of the brand VK-99 at the frequency of $64.9 \mathrm{GHz}$ at room temperature. It is close to the loss in the single crystal $\mathrm{Al}_{2} \mathrm{O}_{3}$ (sapphire).

\section{Acknowledgments}

We are grateful to Ershova P.V (Open Public Company "Plant Magneton", St. Petersburg) for supplying the sample of the aluminium oxide ceramics $\mathrm{Al}_{2} \mathrm{O}_{3}$. 
This work was partially supported by the Russian Foundation for Basic Research, project No. 16-52-53140.

\section{References}

1. Chigryai E.E., Khokhov G.I., and Nikitin I.P., Quasioptical beam splitters on thin dielectric films in the millimeter and submillimeter wave ranges. Zhurnal Radioelektroniki - Journal of Radio Electronics, 2016, No. 6. Available at http://jre.cplire.ru/jre/jun16/9/text.pdf. (In Russian)

2. E.E. Chigryai, B.M. Garin, R.N. Denisyuk, D.S. Kalenov, I.P. Nikitin "Ultralow absorption in silicon carbide in the millimeter wave range", Zhurnal Radioelektroniki - Journal of Radio Electronics, 2016, No. 11. Available at http://jre.cplire.ru/jre/nov16/6/text.pdf.

3. Firsenkov A.I., Kanivets A.Yu., Kasatkina T.S., Ershova O.M., Ivanova L.P., Ershova P.V., Microwave dielectric materials fabricated by Open Public Corporation "Plant Magneton", Sbornik trudov chetvertoi vserossiiskoi konferentsii "Elektronika $i$ mikroelektronika SVCh" [Collected papers of the Fourth All-Russian Conf. "Microwave Electronics and Microelectronics"], St. Petersburg, LETI, 2015, Vol. 2, pp. 55-59. (In Russian)

4. Parshin V.V., Serov E.A., and Ershova P.V., The study of dielectric properties of modern ceramic materials in the millimeter range, Sbornik Trudov Shestoi Vserossiiskoi Konferentsii "Elektronika i mikroelektronika SVCh" [Collected papers of the Sixth All-Russian Conf. "Microwave Electronics and Microelectronics"], St. Petersburg, LETI, 2017, pp. 418-422.

5. Vladimir V. Parshin, Evgeny A. Serov, Evgeny E. Chigryai, Boris M. Garin, Roman N. Denisiuk, Dmitry S. Kalyonov, Mingqing Ding, Lili Li, Yanping Lu, Yanling Yang, Youhuan Liang, Jinjun Feng, and Polina V. Ershova, "Dielectric parameters of the modern low-loss ceramics in the microwave, millimeter, and submillimeter ranges", Zhurnal Radioelektroniki - Journal of Radio Electronics, 2018, No.2, Available at: http://jre.cplire.ru/jre/feb18/10/text.pdf

6. Born M. and Wolf E., Principles of Optics, London: Pergamon Press, 1970, 4th ed. 
7. Dryagin Yu.A., Parshin V.V., A method for determination of dielectric permittivity and loss tangent. The Copyright Certificate No. 1539681, Bull. No. 40, The USSR State Committee for inventions and discoveries, January, 30, 1990. (In Rusian)

8. Dryagin Yu.A., Parshin V.V. A method to measure dielectric parameters in $5 \div 0,5$ mm wavelength band, Int. J. of Infrared and Millimeter Waves. 13 (1992) 1023-1032. 9. S.N. Vlasov, E.V. Koposova, A.B. Mazur and V.V. Parshin. On permittivity measurement by a resonance method. Radiophysics and Quantum Electronics, 1996, Vol. 39, No. 5, pp. 410-415.

10. Parshin V.V., Tretyakov M.Yu., Koshelev M.A., Serov E.A., Instrumental complex and the results of precise measurements of MM and SubMM wave propagation in condensed media and atmosphere. Radiophysics and Quantum Electronics, 2012, Vol. 52, No. 8, pp. 525-535.

11. Parshin V.V., Tretyakov M.Yu., Koshelev M.A., Serov E.A., Modern resonator spectroscopy at submillimeter wavelengths. IEEE Sensors Journal, 2013, Vol. 13, No. 1, pp. 18-23.

12. Parshin V.V., Serov E.A., Precision methods of research of dielectrics and metals in the range of $40-500 \mathrm{GHz}$ and in the temperature range 4-900 K., Sbornik Trudov Chetvertoi Vserossiiskoi Konferentsii "Elektronika i mikroelektronika SVCh" [Collected papers of the Forth All-Russian Conf. "Microwave Electronics and Microelectronics"], St. Petersburg, LETI, 2015, pp. 34-39., ISBN 978-5-76-29-16349. (In Russian)

\section{For citation:}

E. E. Chigryai, B. M. Garin, R. N. Denisyuk. Measurement of dielectric loss at millimeter range in the low loss materials with arbitrary ratio of wavelength and sample thickness. Zhurnal Radioelektroniki - Journal of Radio Electronics. 2018. No. 10. Available at http://jre.cplire.ru/jre/oct18/10/text.pdf

DOI 10.30898/1684-1719.2018.10.10 